\title{
Implementasi Konsep Pendidikan Karakter Ki Hajar Dewantara Berbasis Nilai-Nilai Pancasila Bagi Mahasiswa Generasi Mileneal
}

\author{
Sigit Sapto Nugroho ${ }^{1}$, Mohammad Choirul Anam ${ }^{2}$, Moch. Juli Pudjiono ${ }^{1}$, \\ Mudji Rahardjo ${ }^{1}$, Bambang Sukarjono ${ }^{1}$ \\ ${ }^{1}$ Fakultas Hukum, Universitas Merdeka Madiun, Jl. Serayu No.79, Madiun, 63133 \\ E-mail: sigitsapto@unmer-madiun.ac.id \\ ${ }^{2}$ Fakultas Hukum, Universitas Merdeka Madiun, Jl. Serayu No.79, Madiun, 63133 \\ E-mail: -
}

\begin{abstract}
Pancasila as the state ideology is the basic reference for all Indonesian citizens in various sectors of life. However, the fact is that currently the noble values of Pancasila are increasingly being eroded due to the influence of globalization and the rapid progress of science, technology and art which are not well filtered. To restore the value of Pancasila in the life of society, nation and state, it is necessary to implement the values of Pancasila based on character education. The purpose of writing this scientific paper is to discuss the values of national character based on Pancasila and the concept of character education based on Pancasila values for millennial generation students. The data collection method used was literature review with descriptive-critical analysis techniques. Based on the results of the research, it shows that the values contained in the Pancasila ideology can be used as a basis for character education for students, especially the millennial generation, which in its implementation uses the concept of character education from Ki Hadjar Dewantara which includes the Among and Tri-Nga systems based on the educational Tripusat, namely family, school and community.
\end{abstract}

Keywords—: Pancasila Values; Character Education; Milineal Students dispute.

\section{PENDAHULUAN}

Persaingan antar produsen saat ini demikian ketat dan yang dihadapi bukan lagi competitor dalam negeri. Hal ini berarti, konsumen mempunyai banyak pilihan terhadap produk barang/jasa yang dikonsumsinya. Tentu mereka memilih yang terbaik di antara semua produk barang/jasa yang tersedia. Itu berarti masalah terbaik mutu barang dari jumlah ketersedianya di pasaran tidak lagi menjadi keprihatinan utama karena produsen dengan sendirinya berlomba-lomba untuk memenuhinya. Jika tidak, produsen demikian akan kalah dalam persaingan. ${ }^{1}$

Mahasiswa atau Generasi muda atau lebih dikenal sebagai generasi milineal bangsa merupakan generasi penerus pemegang estafet kepemimpinan. Bangsa Indonesia harus menjaga dan mempraktikkan nilai-nilai pancasila bagi kehidupan masyarakat ${ }^{2}$. Negara di masa depan harus terus mempertahankan karakter bangsa. Era revolusi industri 4.0 memungkinkan kemajuan ilmu pengetahuan, teknologi dan seni begitu cepat mempengaruhi kehidupan bangsa Indonesia. Kemajuan ini menuntut generasi bangsa untuk dapat menyesuaikan akan perkembangannya. Keinginan kita untuk selalu maju agaknya banyak berdampak dan membawa pengaruh bagi bangsa ini, baik itu berupa dampak positif maupun negatif.

Di era ini diikuti dengan adanya trend yang semakin dinamis dan selalu diwarnai oleh ketidakteraturan dan ketidakpastian. Kondisi ini menimbulkan kecenderungan permasalahan baru yang semakin beragam dan multi dimensional ${ }^{3}$. Berbagai dekadensi moral seperti kriminalitas, semakin banyaknya korupsi, kolusi dan nepotisme, radikalisme, kejahatan seksual, kehidupan yang konsumtif, kehidupan politik yang tidak produktif, dan lain-lain yang seringkali menjadi wacana hangat dan tiada hentinya untuk dibicarakan. Hingga saat ini fenomena tersebut seakan-akan merupakan hal yang biasa dan akrab di dengar oleh masyarakat kita. Fenomena dekadensi moral dapat terjadi karena suatu bangsa kehilangan jati dirinya, dimana mereka tidak dapat mempertahankan apa yang menjadi identitasnya selama ini ${ }^{4}$. Mereka terlalu terlena dan kurang dapat memfilter budaya yang masuk ke Indonesia.

Pada hakekat sesungguhnya, bangsa ini memiliki pancasila, pancasila merupakan karakter bangsa yang kini dikalangan mahasiswa generasi milineal semangatnya mulai memudar akan kesadaran untuk menghayatinya. Mulai dari sila pertama

\footnotetext{
${ }^{1}$ Shidarta, 2000, Hukum Perlindungan Konsumen, Grasindo, Jakarta, hal. 29

${ }^{2}$ Asmaroini, A. P. (2017). Menjaga Eksistensi Pancasila dan Penerapannya Bagi Masyarakat Di Era Globalisasi. JPK: Jurnal Pancasila dan Kewarganegaraan, 1(2), Hal 50.

${ }^{3}$ Agung, I. (2010). Perspektif Multidimensional Pendidikan Pembangunan Berkelanjutan: Pemikiran Awal Konsep dan Penerapan. Jurnal Pendidikan dan Kebudayaan, 16(4), Hal 453.

${ }^{4}$ Tulus, M. (2013). Konfigurasi Pendidikan Karakter Berparadigma Kebangsaan; Usaha Meneguhkan Identitas Diri Bangsa dari Kungkungan Arus Globalisasi. el-hikmah, (2), Hal 258.
} 
hingga ke lima, semuanya mencakup berbagai lini kehidupan yang dijalani manusia, oleh sebab itu, sudah semestinya kita perlu meneguhkan kembali jati diri bangsa ini, melalui Pancasila.

Dalam mewujudkan mahasiswa generasi milineal yang menjunjung tinggi nilai pancasila dalam praktik kehidupan sehari hari maka hal ini dapat diawali dengan menerapkan sistem pendidikan karakter yang tepat terlebih dahulu. Dengan memberikan suatu konsep pengajaran pendidikan karakter yang tepat bagi generasi muda, maka diharapkan di masa depan dapat mewujudkan mahasiswa generasi milineal yang memiliki karakter sesuai dengan kepribadian pancasila dan cinta tanah air.

Ki Hadjar Dewantara adalah pemikir pendidikan modern dan juga dikenal sebagai Bapak Pendidikan Nasional Indonesia, yang dikenal dengan konsep pranata pendidikanya yang sampai saat ini masih tetap eksis berdiri yaitu Perguruan Nasional Tamansiswa yang didirikan di Yogyakarta pada tanggal 3 Juli 1922. Pemikiran pendidikan Ki Hadjar Dewantara sebenarnya juga tidak kalah dengan pemikiran dan teori pendidikan modern.

Ki Hadjar Dewantara merupakan sosok anak bangsa Indonesia, tokoh pendidikan yang banyak mengajarkan berbagai hal dalam pembentukan karakter bangsa dan sangat membumi serta berakar pada budaya nusantara antara lain Sistem Among, Tripusat pendidikan dan konsep Tri- Nga yang terdiri dari Ngerti (kognitif), Ngrasa (afektif) dan Nglakoni (psikomotorik) dari Taxonomy Bloom (cognitive, affective, psychomotor), sehingga beliau dikenal sebagai pejuang, pendidik sejati dan sekaligus budayawan Indonesia.

Berdasarkan fenomena tersebut penulis ingin menguraikan yang dilandasi beberapa rumusan masalah sebagai batasan bahasan yang diantaranya sebagai berikut:

1. Apa saja nilai-nilai Pancasila sebagai dasar pendidikan karakter bagi mahasiswa generasi milineal?

2. Bagaimana konsep pendidikan karakter dalam perspektif Ki Hadjar Dewantara berbasis nilai-nilai Pancasila?

\section{METODE PENELITIAN}

Artikel ini didasarkan pada studi kepustakaan atau library research. Library research adalah rentetan aktivitas penelitian yang berkaitan dengan bagaimana cara dan metode yang tepat dalam pengumpulan data kajian, menafsirkan dan mendaftar serta menyiapkan komposisi kajian yang dibahas. Hal ini merupakan suatu penelitian yang memanfaatkan sumber perpustakaan untuk memperoleh data penelitiannya. Dalam artikel ini, penulis menggunakan metode penelitian deskriptif kualitatif-kritis. Penelitian deskriptif-kritis dengan lebih menekankan pada kekuatan analisis sumber-sumber dan data-data yang bergantung pada teori-teori dan naskah-naskah yang ada untuk diterjemahkan berlandaskan tulisan-tulisan yang mengarah kepada diskusi utama. Landasan-landasan di atas didapat dari karya yang ditulis oleh intelektual dan ahli yang berkompeten ${ }^{5}$.

\section{III.PEMBAHASAN}

\section{A. Nilai-Nilai Pancasila sebagai Dasar Pendidikan Karakter Mahasiswa Generasi Milineal}

Nilai materiil Pancasila merupakan sumber kekuatan bagi perjuangan bangsa Indonesia. Nilai-nilai Pancasila merupakan pengikat sekaligus pendorong dalam usaha menegakkan dan memperjuangkan kemerdekaan sehingga menjadi bukti bahwa Pancasila sesuai dengan kepribadian dan keinginan bangsa Indonesia. Pancasila merupakan sublimasi nilai-nilai budaya yang menyatukan masyarakat Indonesia yang beragam suku, ras, bahasa, agama, pulau, menjadi bangsa yang satu.

Nilai-nilai yang terkandung di dalam Pancasila merupakan jiwa kepribadian, dan pandangan hidup masyarakat di wilayah nusantara sejak dahulu. Hingga kini, nilai-nilai budaya tersebut melandasi tata kehidupan masyarakat Indonesia.

Aktualisasi nilai pancasila perlu disosialisasikan, diinternalisasikan dan diperkuat implementasinya, dalam praktik kehidupan berbangsa dan bernegara dengan memperkuat karakter generasi bangsa dalam berperan serta membangun pemahaman masyarakat akan kesadaran nasional. Aktualisasi nilai dalam praktek kehidupan berbangsa dan bernegara mengarahkan adanya 3 nilai yang terkandung dalam ideologi Pancasila. Tiga nilai itu adalah ${ }^{6}$ :

1. Nilai dasar, yaitu prinsip, yang bersifat sangat abstrak, bersifat sangat umum, tidak terikat oleh waktu dan tempat, dengan kandungan kebenaran yang bagaikan aksioma. Dari aspek kandungan nilainya, maka nilai dasar berkenaan dengan eksistensi sesuatu, yang mencakup cita-cita, tujuan, tatanan dasar dan ciri khasnya.

2. Nilai instrumental, yaitu suatu nilai yang bersifat kontekstual. Nilai instrumental merupakan penjabaran dari nilai dasar tersebut, yang merupakan arahan kinerjanya untuk kurun waktu tertentu dan untuk kondisi tertentu.

3. Nilai praksis, yaitu nilai yang terkandung dalam kenyataan sehari-hari, berupa cara bagaimana rakyat mengaktualisasikan nilai Pancasila. Bagi suatu ideologi, yang paling penting adalah bukti pengamalannya atau aktualisasinya dalam kehidupan bermasyarakat, berbangsa, dan bernegara. Jika pada nilai praksisnya tidak dapat diaktualisasikan, maka ideologi tersebut akan kehilangan kredibilitasnya

Pancasila merupakan refleksi kritis dan rasional sebagai dasar negara dan kenyataan budaya bangsa, dengan tujuan untuk mendapatkan pokok-pokok pengertiannya secara mendasar dan menyeluruh. Pancasila sebagai ideologi baik dalam pengertian

\footnotetext{
${ }^{5}$ Kariyadi, D. (2017). Membangun Kepemimpinan Berbasis Nilai-Nilai Pancasila Dalam Perspektif Masyarakat Multikultural. Citizenship Jurnal Pancasila Dan Kewarganegaraan, 5(2), Hal 87.

${ }^{6}$ Alaby, M. A. (2019). Membumikan Nilai Pancasila pada Generasi Bangsa. Gema Wiralodra, 10(2), Hal 184-185.
} 
ideologi negara atau ideologi bangsa masih dipertahankan khususnya sebagai dasar pendidikan karakter. Oleh karena itu, pendidikan karakter di Indonesia dalam praksisnya mesti berangkat dari pokok-pokok berikut ${ }^{7}$ :

Pertama, berlandaskan ketaqwaan dan toleransi. Percaya kepada Tuhan yang Maha Esa secara vertikal mencerminkan kerinduan manusia untuk mencapai keutuhan dirinya pada Tuhan. Tapi secara horizontal mengharuskan manusia di Indonesia untuk menghormati keragaman cara ber-Tuhan sebagai anugerah atau keinginan Tuhan. Dalam praksis hidup bersama, pluralitas yang dimaksudkan menuntut masing-masing pihak untuk berkontribusi dalam menciptakan kondisi hidup yang harmonis, damai, dan saling menghormati perbedaan identitas keagamaan. Secara historis ajakan untuk saling menghormati itu berlandaskan pada aneka ragam pernyataan Bung Karno yang bukan hanya menghendaki agar orang Indoesia percaya pada Tuhan atau ber-Tuhan, tapi menegaskan agar Negara Indonesia adalah Negara yang ber-Tuhan. Konsekuensinya, bangsa Indonesia harus saling menghormati cara dalam ber-Tuhan. Kedewasaan iman kepada Tuhan adalah ruh yang menghidupkan sikap toleransi dalam beragama; yang juga mendorong dan menggerakan manusia di Indonesia untuk bertanggungjawab dalam memelihara kelestarian lingkungan hidupnya.

Kedua, dimaksudkan untuk memupuk rasa persaudaraan atas dasar hormat pada kemanusiaan. Iman kita kepada Tuhan menjadi nyata memuliakan diri-Nya melalui sikap dan tindakan konkret kita terhadap sesama manusia yang konstruktif. Jadi, iman kepada Tuhan Yang Maha Esa mendukung dan mengharuskan kita untuk menghormati kemanusiaan orang lain; hidup bersaudara dengan siapapun juga dan hormat terhadap martabat kehidupan manusia. Implementasi iman seperti itu menghantar setiap orang (Indonesia) kepada kondisi hidup yang adil dan beradab. Dengan demikian, kecenderungan pada tindak yang merendahkan harkat dan martabat kemanusiaan berupa kekerasan dalam berbagai bentuk dan alasannya dapat dikurangi.

Ketiga, menumbuhkan sikap rela berkorban atas dasar komitmen dan cinta pada tanah air. Sikap rela berkorban demi nusa dan bangsa mengisyaratkan kesediaan semua pihak untuk menempatkan kepentingan negara (nusa dan bangsa) di atas kepentingan pribadi dan golongan. Ini berarti bahwa, kecenderungan untuk korupsi dan sikap primordial berdasarkan suku, agama, ras, dan antar-golongan yang menghambat pembangunan dan memperlemah persatuan bangsa, dan membuyarkan kebersamaan dalam keragaman perlu ditinggalkan.

Keempat, menegaskan pentingnya musyawarah untuk menentukan dan mengambil keputusan bersama. Kemauan untuk bermusyawarah dan sikap rela berkorban mencitrakan sosok manusia yang bijaksana, yang sanggup meninggalkan egoisme dirinya dan terbuka hati dan budinya untuk mendengarkan pandangan pihak lain dan bermusyawarah demi mencapai kesepakatan yang berguna untuk mencapai cita-cita hidup bersama.

Kelima, membangun solidaritas sosial berupa kepedulian dan keterlibatan sosial secara aktif (berbelarasa) untuk mengeluarkan sesama manusia dari kondisi-kondisi hidup yang tidak manusiawi karena kemiskinan. Manusia yang bijaksana adalah manusia yang mampu berlaku adil dan berbelarasa kepada sesamanya yang menderita. Berdasarkan pokok-pokok di atas, tampak bahwa pendidikan karakter dalam praksis adalah upaya untuk "membebaskan" para peserta didik dari sikap picik dan egois sehingga mereka mau maju bersama dalam rangka menjawab tantangan-tantangan kultur globalisasi secara konstruktif bagi diri sendiri, sesama dan lingkungan.

Melihat nilai-nilai yang terkandung dalam Pancasila tersebut, maka pendidikan karakter yang dikembangkan memang mengarah kepada nilai tersebut yang intinya untuk membentuk bangsa yang tangguh, kompetitif, berakhlak mulia, bermoral, bertoleran, bergotong royong, berjiwa patriotik, berkembang dinamis, berorientasi ilmu pengetahuan dan teknologi yang semuanya dijiwai oleh iman dan takwa kepada Tuhan yang Maha Esa.

\section{B. Konsep Pendidikan Karakter Ki Hadjar Dewantara berbasis Nilai-Nilai Pancasila}

Ki Hadjar Dewantara selalu memandang pendidikan sebagai upaya pemerdekaan lahiriah dan batiniah manusia. Itulah sebabnya Bapak Pendidikan Nasional bangsa Indonesia itu meletakan kerangka pendidikan karakternya pada asas-asas yang disebut Pancadharma (asas kodrat alam, asas kemerdekaan, asas kebudayaan, asas kebangsaan, dan kemanusiaan). Kelima asas itu mengisyaratkan agar pendidikan menyadarkan manusia akan kodrat dirinya yang tunduk pada hukum alam, pentingnya menghargai kemerdekaan orang lain, meneruskan budaya leluhur dan hidup selaras dengan nilai-nilainya, menyokong atau berpartisipasi aktif dalam menjaga kesatuan bangsa, serta menjadi saudara bagi siapapun juga sebagai manusia di seantero dunia ini.

Praksis pendidikan karakter berdasarkan asas-asas itu tentu harus mencerminkan nilai-nilai Keindonesiaan seperti Ketuhanan, persaudaraan, kekeluargaan dan gotong royong, musyawarah dan mufakat, serta hormat pada hak-hak sesama. Secara lengkap barangkali itulah yang dikristalisasi sebagai Pancasila. Singkatnya, ruh pendidikan karakter mesti menampilkan kekhasan kultur dan keunikan Indonesia. Dalam konteks itu, asas-asas dan semboyan pendidikan Ki Hadjar Dewantara yang pada intinya menyangkut kemanusiaan dan manusia yang harus berperikemanusiaan dan beradab dalam konteks kehidupan personal dan komunal, nasional dan internasional penting dihidupkan. Oleh karena itu, landasan nilai bagi pendidikan karakter di Indonesia mestilah berangkat dari konsep dan melanjutkan perjuangan Ki Hadjar Dewantara itu.

Begitu pentingnya pendidikan karakter, sehingga Ki Hadjar Dewantara menjadikan hal ini sebagai jiwa dari konsep pendidikannya. Ajaran Ki Hadjar Dewantara terdiri dari beberapa hal yang bersifat konsepsional, petunjuk operasional-praktis, fatwa, nasihat dan sebagainya. Berikut adalah beberapa konsep dan ajaran dari Ki Hadjar Dewantara:

$$
\text { 1. Sistem Among }
$$

\footnotetext{
${ }^{7}$ Samho, B. (2014). Pendidikan Karakter dalam Kultur Globalisasi: Inspirasi dari KI Hadjar Dewantara. Melintas, 30(3), Hal. 295-296.
} 
Konsep pendidikan Ki Hajar Dewantara disebut dengan konsep pendidikan Sistem Among yang meliputi Ing Ngarsa Sung Tuladha (jika di depan memberi teladan mengandung nilai keteladanan, pembimbingan dan pemanduan), Ing Madya Mangun Karsa (jika ditengah-tengah atau sedang bersama-sama menyumbangkan gagasan, yang bermakna peserta didik didorong untuk mengembangkan karsa atau gagasannya-mengandung nilai kreativitas dan pengembangan gagasan serta dinamisasi pendidikan) dan Tut Wuri Handayani (jika dibelakang menjaga agar tujuan pendidikan tercapai dan peserta didik diberi motivasi serta diberi dukungan psikologis untuk mencapai tujuan pendidikan - mengandung nilai memantau, melindungi, merawat, menjaga, memberikan penilaian dan saran-saran perbaikan, sambil memberikan kebebasan untuk bernalar dan mengembangkan karakter peserta didik) sebenarnya sarat akan nilai-nilai karakter ${ }^{8}$.

Konsep Sistem Among Ki Hajar Dewantara kemudian diadopsi ke dalam konsep Kaya Karsa, sehingga pendidikan karakter sebetulnya bukan hal yang baru, tetapi merupakan penggalian nilai-nilai lama dari konsep pendidikan Ki Hajar Dewantara. Pendidik dapat menjadi contoh yang langsung dapat ditiru oleh peserta didik dengan mengikuti ajaran dan fatwa Ki Hajar Dewantara dengan menonjolkan karakter?

a) Tetep-Mantep-Antep

1) Tetep mempunyai makna bahwa dalam melaksanakan tugas kependidikan dan pembangunan bangsa harus berketetapan hati. Tekun bekerja tanpa menoleh kanan kiri yang berarti melenakan perjuangan.

2) Mantep berarti tetap tertib berjalan maju selalu setia dan taat asas, teguh iman sehingga tidak ada kekuatan yang dapat dapat menahan gerak dan langkah kita.

3) Antep berarti segala perbuatan dan tindak laku kana berisi dan berharga, tidak mudah dihambat dan dirintangi orang lain.

b) Ngandel, Kendel, Bandel, Kandel.

1) Ngandel, Maknanya, kita harus percaya dan yakin sepenuhnya, pada kekuasaan dan takdir serta pada kekuatan serta kemampuan diri sendiri.

2) Kendel artinya berani, berani menghadapi segala sesuatu yang merintangi, tidak ada ketakutan, was was dan keraguan hati karena Ngandel.

3) Bandel artinya kokoh, teguh hati tahan banting disertai sikap tawakal dan kehendak Tuhan.

4) Kandel berarti tebal serta kuat lahir batin sebagai kekuatan untuk menuju cita-cita.

c) Neng-Ning-Nung-Nang

1) Neng-meneng berarti tidak ragu dan malu

2) Ning-wening berarti bening, jernih pikiran, tidak mengedepankan emosi, mampu dan mudah membedakan antara yang hak dan yang batil.

3) Nung - hanung berarti kokoh, senantiasa kuat, teguh dan kukuh lahir batin

4) Nang - menang dan wenang berarti memperoleh kemenangan dan memiliki kewenangan berhak dan berkuasa memiliki hasil jerih payah kita.

Apabila pendidik mampu mengimplementasikan ajaran Ki Hajar Dewantara untuk mencapai fungsi dan tujuan dari

Kaya Karsa maka dapat dipastikan pendidikan karakter bangsa tidak akan hanya menjadi wacana saja tetapi dapat dijadikan contoh kepada generasi muda sehingga menjadi panutan.

2. Tri-Nga (Ngerti-Ngrasa-Ngalokoni)

Ki Hadjar Dewantara juga disebut Sang Maestro Pendidikan Indonesia karena telah meletakkan fondasi dasar konsepkonsep dan pemikirannya tentang pendidikan. Pemikiran beliau tentang pendidikan yang diperkenalkan jauh-jauh hari sebelum kemerdekaan Indonesia masih sangat relevan dengan kondisi yang terjadi saat ini.

Pemikiran pendidikan Ki Hadjar Dewantara juga tidak kalah dengan pemikiran dan teori pendidikan modern. Misalnya, Ki Hadjar Dewantara jauh lebih dulu mengenalkan konsep Tri- Nga dari Taxonomy Bloom (cognitive, affective, psychomotor) yang terkenal. Makna dari konsep ajaran Tri-Nga tersebut adalah ${ }^{10}$ :

a) Ngerti (mengetahui)

maknanya bahwa tujuan pendidikan adalah untuk meningkatkan pengetahuan peserta didik tentang apa yang dipelajari;

b) Ngrasa (memahami)

yang maknanya mengasah rasa tentang pemahaman tentang apa yang diketahui, dan;

c) Nglakoni (melakukan)

yaitu meningkatkan kemampuan untuk melaksanakan apa yang dipelajari.

Jadi pada intinya dalam Pendidikan karakter itu merupakan proses untuk membentuk, menumbuhkan, mengembangkan dan mendewasakan kepribadian anak menjadi pribadi yang bijaksana dan bertanggung jawab melalui pembiasaanpembiasaan pikiran, hati dan tindakan secara berkesinambungan yang hasilnya dapat terlihat dalam tindakan nyata sehari-hari baik di sekolah, keluarga, maupun di masyarakat.

3. Tri Pusat Pendidikan

\footnotetext{
${ }^{8}$ Samani, M., \& Hariyanto, M. S. (2011). Konsep dan model pendidikan karakter. Bandung: Remaja Rosdakarya, Hal 6.

${ }^{9}$ Rachmah, H. (2013). Nilai-nilai dalam pendidikan karakter bangsa yang berdasarkan Pancasila dan UUD 1945. E-Journal WIDYA Non-Eksakta, 1(1), Hal 13.

${ }^{10}$ Zulfiati, H. M. (2019, June). Pendidikan Karakter Perspektif Ki Hadjar Dewantara Dalam Membentuk Generasi Unggul Era Revolusi Industri 4.0. In Prosiding Seminar Nasional PGSD UST (Vol. 1), Hal 4.
} 
Pendidikan karakter tidak akan berhasil dengan baik apabila hanya satu pusat pendidikan yang berjalan. Aktualisasi nilai pancasila harus mulai disosialisasikan dari berbagai lingkungan pendidikan. Istilah Tri Pusat Pendidikan adalah istilah yang digunakan oleh tokoh pendidikan Indonesia, yaitu Ki Hajar Dewantara. Di semua lingkungan pendidikan tersebut harus dibumikan dengan nilai- nilai Pancasila, seperti halnya dibawah ini ${ }^{11}$ :

a) Pendidikan dalam Keluarga

Dalam lingkungan lembaga pendidikan Informal seperti Keluarga. Tahap pendidikan yang pertama dan utama bagi anak ada di keluarga, Artinya bagaimana karakter anak berkembang kedepan bergantung dari pola asuh yang diterapkan di rumah. Apakah pola asuh permisif yang memberi kebebasan pada anak, pola asuh otoriter yang mewajibkan anak untuk selalu patuh, atau pola asuh autoritatif yang artinya antara orangtua dan anak saling mengerti tanggungjawab, hak dan kewajiban masing-masing. Selanjutnya untuk menanamkan moral yang baik pada anak, orang tua juga harus memiliki karakter yang tentu saja lebih baik terlebih dahulu, dengan begitu orangtua seakan menjadi teladan atau row model bagi anak dalam bertindak sehingga anak senantiasa berhati-hati dalam bertingkah laku.

b) Pendidikan dalam Sekolah

Pendidikan dalam sekolah adalah jalur pendidikan yang terstruktur dan berjenjang yang terdiri atas pendidikan dasar, pendidikan menengah, dan pendidikan tinggi. Dalam lingkungan lembaga pendidikan Formal / Sekolah. Dalam membentuk karakter peserta didik peran tenaga pendidik sangat penting, Para tenaga pendidik yang merupakan orangtua kedua peserta didik di sekolah, perlu senantiasa mengimplementasikan nilai-nilai Pancasila yang sebenarnya. Mulai dari kebiasaan untuk berdoa setiap kegiatan belajar mengajar, saling toleransi antar teman, menumbuhkan sikap peduli sesama, dan tidak membeda- bedakan antara peserta didik satu dengan peserta didik yang lain.

c) Pendidikan dalam Masyarakat

Mengimplementasikan nilai-nilai Pancasila di masyarakat tentu dimulai dari sekitar lingkungan rumah. Keberagaman etnis yang ada di masyarakat hendaknya menjadi suatu warna tersendiri bagi mereka, sebagaimana semboyan yang dimiliki bangsa Indonesia yaitu " Bhinneka Tunggal Ika, walaupun negara Indonesia terdiri dari beragam suku, namun kerukunan antar seluruh umat di Indonesia tetap perlu dijunjung tinggi.

Dengan cara kembali melakukan aktualisasi nilai - nilai pancasila di berbagai aspek moral bangsa Indonesia dengan menggunakan konsep pengajaran berdasarkan perspektif Ki Hadjar Dewantara dengan tepat, diharapkan generasi muda bangsa dapat kembali menuju jati dirinya. Nilai pancasila tersebut akan terimplementasi dalam ranah kognitif, afektif dan psikomotorik bangsa. Hal demikian sangat penting untuk diingat karena dapat menjadi parameter atau tolak ukur sampai seberapa jauh tingkat perubahan tingkah laku seseorang, dan untuk mengetahui tingkat ketercapaian dalam menempuh proses pendidikan. Sehingga pada akhirnya dapat benar-benar menghasilkan output yang cerdas, unggul, berdaya saing, bermoral, berkarakter dan cinta tanah air berlandaskan nilai-nilai Pancasila.

\section{IV.KESIMPULAN}

1. Aktualisasi nilai pancasila perlu disosialisasikan, diinternalisasikan dan diperkuat implementasinya, dalam praktik kehidupan berbangsa dan bernegara dengan memperkuat karakter bagi mahasiswa generasi milineal berdasarkan tiga nilai yang terkandung dalam ideologi Pancasila yaitu Nilai Dasar, Nilai Instrumental, dan Nilai Praksis. Oleh karena itu, pendidikan karakter di Indonesia dalam praksisnya mesti berangkat dari pokok-pokok berikut yaitu: Pertama, berlandaskan ketaqwaan dan toleransi; Kedua, dimaksudkan untuk memupuk rasa persaudaraan atas dasar hormat pada kemanusiaan; Ketiga, menumbuhkan sikap rela berkorban atas dasar komitmen dan cinta pada tanah air; Keempat, menegaskan pentingnya musyawarah untuk menentukan dan mengambil keputusan bersama; Kelima, membangun solidaritas sosial berupa kepedulian dan keterlibatan sosial secara aktif (berbelarasa) untuk mengeluarkan sesama manusia dari kondisi-kondisi hidup yang tidak manusiawi karena kemiskinan.

2. Praksis pendidikan karakter harus mencerminkan nilai-nilai Keindonesiaan sehingga Ki Hadjar Dewantara menjadikan Pancasila ini sebagai jiwa dari konsep pendidikannya yang meliputi: Sistem Among yang meliputi Ing Ngarso Sung Tulodho, Ing Madya Mangunkarsa, Tut Wuri Handayani; Tri-Nga yang meliputi Ngerti, Ngrasa, Nglakoni yang berbasis Tripusat Pendidikan yang meliputi keluarga, sekolah dan masyarakat.

\section{DAFTAR PUSTAKA}

\section{A. Buku}

Samani, M. Hariyanto, 2011, “Konsep dan Model” Pendidikan Karakter, Bandung: PT. Remaja Rosdakarya.

\footnotetext{
${ }^{11}$ Alaby, M. A. (2019). Membumikan Nilai Pancasila pada Generasi Bangsa. Op Cit. Hal 186
} 
Website : http://yustisia.unmermadiun.ac.id/index.php/yustisia

\section{B. Jurnal}

Agung, I. (2010). Perspektif Multidimensional Pendidikan Pembangunan Berkelanjutan: Pemikiran Awal Konsep dan Penerapan. Jurnal Pendidikan dan Kebudayaan, 16(4), 453-468.

Alaby, M. A. (2019). Membumikan Nilai Pancasila pada Generasi Bangsa. Gema Wiralodra, 10(2), 179-190.

Asmaroini, A. P. (2017). Menjaga Eksistensi Pancasila dan Penerapannya Bagi Masyarakat Di Era Globalisasi. JPK: Jurnal Pancasila dan Kewarganegaraan, 1(2), 50-64.

Kariyadi, D. (2017). Membangun Kepemimpinan Berbasis Nilai-Nilai Pancasila Dalam Perspektif Masyarakat Multikultural. Citizenship Jurnal Pancasila Dan Kewarganegaraan, 5(2), 86-96.

Rachmah, H. (2013). Nilai-nilai dalam pendidikan karakter bangsa yang berdasarkan Pancasila dan UUD 1945. E-Journal WIDYA Non-Eksakta, 1(1).

Samho, B. (2014). Pendidikan Karakter dalam Kultur Globalisasi: Inspirasi dari KI Hadjar Dewantara. Melintas, 30(3), $285-302$.

Tulus, M. (2013). Konfigurasi Pendidikan Karakter Berparadigma Kebangsaan; Usaha Meneguhkan Identitas Diri Bangsa dari Kungkungan Arus Globalisasi. el-hikmah, (2).

Zulfiati, H. M. (2019, June). Pendidikan Karakter Perspektif Ki Hadjar Dewantara Dalam Membentuk Generasi Unggul Era Revolusi Industri 4.0. In Prosiding Seminar Nasional PGSD UST (Vol. 1). 